\title{
Design a New Receiver for the Central Tower of Solar Energy
}

\author{
Ayad K. Khlief ${ }^{1,2, *}$, Syed I. U. Gilani ${ }^{1}$, Hussain H. Al-Kayiem ${ }^{1}$, Sanan T. Mohammad ${ }^{1}$ \\ ${ }^{1}$ Mechanical Engineering Department, Universiti Teknologi PETRONAS, 32610 Bandar Seri \\ Iskandar, Perak, Malaysia \\ ${ }^{2}$ Department of Electromechanical Engineering, University of Technology, Baghdad, Iraq
}

\begin{abstract}
Heat loss is an important factor in the performance of the solar receiver for concentrated solar systems (CSP). This study presents a proposed model for a new design for the receiver using an evacuated tube that has been performed to reduce convection loss and radiative heat losses with a zigzag distribution to minimize spillage losses. In this study, simulation results showed that the energy input increases with increased solar irradiation; the increase ranges from 3429 to $5584 \mathrm{~W}$ and 1879 to 3875 $\mathrm{W}$ at $9 \mathrm{AM}$ and $13 \mathrm{PM}$ for preheater and superheater respectively. The thermal efficiency of the receiver was around $72 \%$.
\end{abstract}

\section{Introduction}

Advanced solar energy technology enables high-grade energy to yield the inefficient amount of power while keeping the plant size compact and offering minimal capital investment recovery period $[1,2]$. Concentrated solar power (CSP) technology is one of the advanced methods to harness the excessive solar energy and has the capability to meet the thermal and electrical energy demands $[3,4]$.

In a solar tower power plant, myriad of heliostats is used to reflect the solar radiation received from the sun towards a tower-mounted central receiver. This central receiver is the most important and crucial component of the solar power plant and contributes the maximum to its overall performance. Its primary function is to absorb the reflected solar energy, which has been also concentrated by heliostats, and to transmit this energy into a Heat Transfer Fluid (HTF). The HTF is then used to rotate a steam turbine or any other prime movers to generate electric power.

The current study proposes a new central receiver design. This design can significantly help in reducing the heat loss from central tower receivers. This study is motivated by the idea of using an evacuated tube in the parabolic trough as a receiver in the central tower plant. Recapitulating, this study was able to identify a correlation model which evaluates the performance and efficiency of the central receiver.

\footnotetext{
*Corresponding Author: atwany.ayad g03200@utp.edu.my
} 


\section{New receiver model}

The new receiver model is based on the reflected area of the heliostat field i.e. the solar collector (eleven evacuation tubes). To evaluate the parameters that determine the performance, a particular place is needed so that the incident solar radiation can be extracted and used as the initial solar energy hypothesis. The site selected to serve this purpose is the Universiti Teknologi PETRONAS, which is located in, Perak, Malaysia.

Fig. 1 shows the hypothetical appearance of the complete setup. The main components of the proposed system are illustrated in Fig.1 (a). Heliostat concentrator with 8 mirrors (dimensions of $2.5 \mathrm{~m} \times 1.25 \mathrm{~m}$ ) and evacuated tube receiver with tower represent the main components of the system. The setup consists of eleven evacuation tubes arranged in a zigzag configuration, in such a pattern that all tubes are in contact with the base frame as shown in Fig.1 (b).

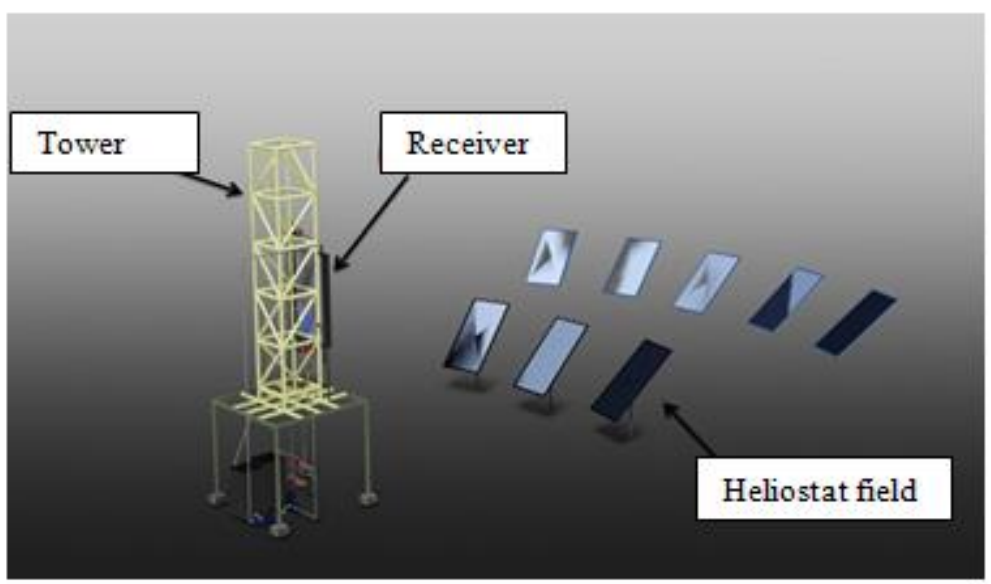

(a)

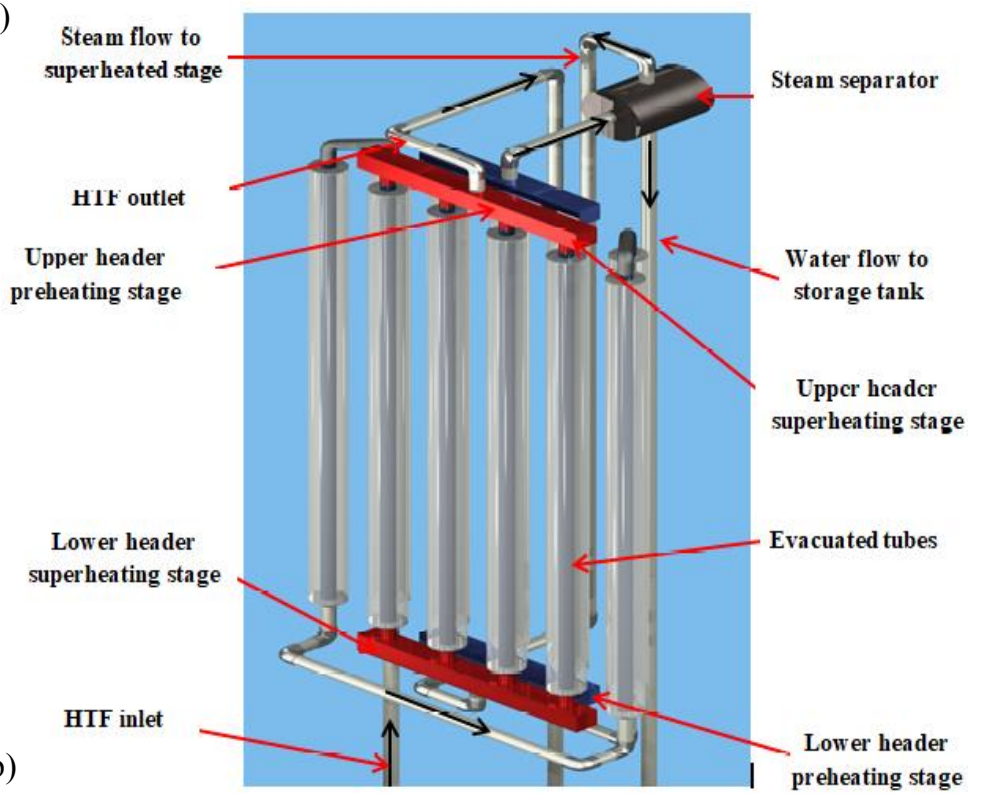

Fig. 1. Schematic diagram of the proposed model (a) heliostat field (b) evacuated tube receiver. 


\section{Mathematical modeling}

The energy from the solar radiation incident on the receiver of the tower is determined by the field efficiency. This incident energy being incident is mathematically determined as $[5]$.

$$
\dot{q}_{\text {inci }}=D N I \times A_{H} \times N_{H} \times \eta_{c o s} \cdot \eta_{s h a} \cdot \eta_{b l o} \cdot \eta_{a t t} \cdot \rho_{r e f}
$$

Where: DNI is the Direct Normal Irradiance, $A_{H}$ is the area of one heliostat, $N_{H}$ is the number of all heliostats in a field while $\eta_{c o s} \cdot \eta_{s h a} \cdot \eta_{b l o} . \eta_{a t t} \cdot \rho_{\text {ref }}$ are the cosine, shadowing, blocking, atmospheric attenuation and mirror reflectance losses, respectively.

A one-dimensional, steady in time, energy balancing for a particular cross-section of $\mathrm{HCE}$ is shown in Fig. 2.

To establish an energy balance between the absorber and HTF, equation 3 has been employed which in turn, results in equation (4).

$$
\begin{gathered}
\dot{q}_{2-1, \text { conv }}=\dot{q}_{2-3, \text { cond }} \\
\mathrm{Nu}_{\mathrm{D} 2} \pi \mathrm{k}_{1}\left(\mathrm{~T}_{2}-\mathrm{T}_{1}\right)=2 \pi \mathrm{k}_{2-3}\left(\mathrm{~T}_{2}-\mathrm{T}_{3}\right) / \ln \left(D_{3} / D_{2}\right)
\end{gathered}
$$$$
\mathrm{T}_{i}
$$

$$
\mathrm{T}_{o}=2 \mathrm{~T}_{1}-
$$

Where: $D_{2}$ is the inside diameter of the absorber pipe $(\mathrm{m}), D_{3}$ is outer absorber surface diameter (m), $\mathrm{T}_{1}$ is the mean (bulk) temperature of the HTF $\left({ }^{\circ} \mathrm{C}\right), T_{2}$ is the inside surface temperature of absorber pipe $\left({ }^{\circ} \mathrm{C}\right), T_{3}$ is outer absorber surface temperature $\left({ }^{\circ} \mathrm{C}\right), N u_{D 2}$ is the Nusselt number based on $D_{2}, K_{2-3}$ is thermal conductance of absorber wall at $T_{2-3}(\mathrm{~W} / \mathrm{m}-\mathrm{K})$, $T_{i}$ is HTF temperature at inlet the of receivthe er $\left({ }^{\circ} \mathrm{C}\right)$ and $T_{o}$ is HTF temperature at the outlet of the receiver $\left({ }^{\circ} \mathrm{C}\right)$.

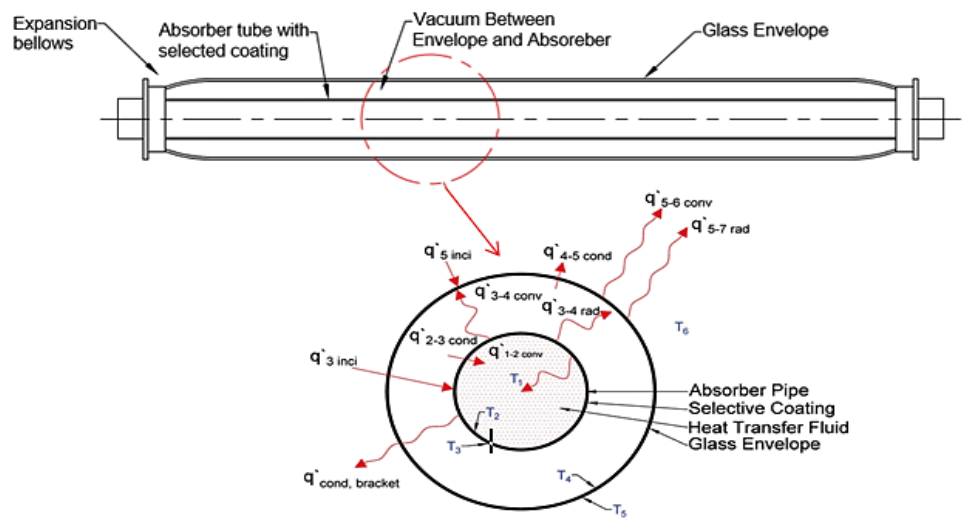

Fig. 2. One-dimensional steady-state energy balance.

For the absorber, the equations for energy balancing are as follow:

$$
\dot{q}_{3, \text { inci }}=\dot{q}_{3-4, \text { conv }}+\dot{q}_{3-4, \text { rad }}+\dot{q}_{2-3, \text { cond }}
$$




$$
\begin{gathered}
\dot{q}_{\text {inci }} \tau_{\text {env }} \alpha_{a b s}=\pi \mathrm{D}_{3} \mathrm{~h}_{3-4}\left(\mathrm{~T}_{3}-\mathrm{T}_{4}\right)+\frac{\sigma \pi \mathrm{D}_{3}\left(\mathrm{~T}_{3}^{4}-\mathrm{T}_{4}^{4}\right)}{\left(1 / \varepsilon_{3}+\left(1-\varepsilon_{4}\right) \mathrm{D}_{3} /\left(\varepsilon_{4} \mathrm{D}_{4}\right)\right)}+ \\
2 \pi k_{2-3}\left(\mathrm{~T}_{2}-\mathrm{T}_{3}\right) / \ln \left(D_{3} / D_{2}\right)
\end{gathered}
$$

Where: $\alpha_{a b s}$ is the absorptance of the absorber, $\tau_{\text {env }}$ is the transmittance of the glass envelope, $D_{4}$ is inner glass envelope surface diameter $(\mathrm{m}), \mathrm{h}_{3-4}$ is convection heat transfer coefficient for the annulus gas at $T_{3-4}\left(\mathrm{~W} / \mathrm{m}^{2} . \mathrm{K}\right)$ and $T_{4}$ is inner glass envelope surface temperature $\left({ }^{\circ} \mathrm{C}\right), K_{3-4}$ is the thermal conductance of annulus gas at $T_{3-4}(\mathrm{~W} / \mathrm{m} . \mathrm{K}), \varepsilon_{3}$ is the absorber selective coating emissivity and $\varepsilon_{4}$ is the glass envelope emissivity

The following section details the mathematical balance of energy between the absorber and glass envelope.

$$
\begin{aligned}
& \dot{q}_{3-4, \text { conv }}+\dot{q}_{3-4, \text { rad }}= \dot{q}_{4-5, \text { cond }} \\
& \pi \mathrm{D}_{3} \mathrm{~h}_{3-4}\left(\mathrm{~T}_{3}-\mathrm{T}_{4}\right)+\frac{\sigma \pi \mathrm{D}_{3}\left(\mathrm{~T}_{3}^{4}-\mathrm{T}_{4}^{4}\right)}{\left(1 / \varepsilon_{3}+\left(1-\varepsilon_{4}\right) \mathrm{D}_{3} /\left(\varepsilon_{4} \mathrm{D}_{4}\right)\right)}= \\
& \quad 2 \pi k_{4-5}\left(\mathrm{~T}_{4}-\mathrm{T}_{5}\right) / \ln \left(D_{5} / D_{4}\right)
\end{aligned}
$$

Where: $k_{4-5}$ is thermal conductance of glass envelope at $T_{4-5}(\mathrm{~W} / \mathrm{m}-\mathrm{K}), T_{5}(\mathrm{~K})$ is the outside the surface temperature of the glass envelope. The subscripts (m) refer to outlet glass envelope surface diameter.

For the balance of energy between the glass envelope and the atmosphere, the following equations have been employed, as listed in this section:

$$
\begin{aligned}
& \dot{q}_{4-5, \text { cond }}+\dot{q}_{5, \text { inci }}=\dot{q}_{5-6, \text { conv }}+\dot{q}_{5-7, \text { rad }} \\
= & 2 \pi k_{4-5}\left(\mathrm{~T}_{4}-\mathrm{T}_{5}\right) / \ln \left(D_{5} / D_{4}\right)+\dot{q}_{\text {inci }} \alpha_{e n v} \\
= & \overline{N u}_{D 5} \pi k_{5-6}\left(\mathrm{~T}_{5}-\mathrm{T}_{6}\right)+\sigma \mathrm{D}_{5} \pi \varepsilon_{5}\left(\mathrm{~T}_{5}^{4}-\mathrm{T}_{7}^{4}\right)
\end{aligned}
$$

$\dot{q}_{\text {inci }}$ is the solar incidence per receiver length $(\mathrm{W} / \mathrm{m})$ and $\alpha_{e n v}$ is the absorptance of the glass envelope (Pyrex glass), $T_{6}(\mathrm{~K})$, represent the ambient temperature, respectively. $k_{5-6}$ is the thermal conductance of air at $\left(T_{5}-T_{6}\right) / 2(\mathrm{~W} / \mathrm{m}-\mathrm{K})$, and $\overline{N u}_{D 5}$ is the average Nusselt number based on the glass envelope outer diameter. $\varepsilon_{5}$ is the glass envelope outer surface emissivity and $\sigma$ is the Stefan Boltzmann's constant $(5.670 \mathrm{E}-8)\left(\mathrm{W} / \mathrm{m}^{2}-\mathrm{K}\right)$, respectively. $T_{7}$ is effective sky temperature $(\mathrm{K})$

$$
\begin{gathered}
\dot{q}_{\text {loss }}=\dot{q}_{5-6, \text { conv }}+\dot{q}_{5-7, \text { rad }}+\dot{q}_{\text {spillage }} \\
\dot{q}_{\text {gain }}=\dot{q}_{\text {inci }}-\dot{q}_{\text {loss }}
\end{gathered}
$$

Where: $q^{\prime}$ loss and $q_{\text {gain }}^{\prime}$ are heat loss per unit receiver length $(\mathrm{W} / \mathrm{m})$.

The thermal efficiency can thus be calculated utilizing the following equation;

$$
\eta_{\text {thermal }}=\frac{\dot{q}_{\text {gain }}}{\dot{q}_{\text {inci }}}
$$

The set of above-mentioned equations are solved in MATLAB employing an implicitly iterative approach. And a boundary analysis was performed on the system (shown in Fig. 1, b). The JJR-T-2140 was used as a tube collector. 


\section{Result and discussion}

Fig. 3 shows the solar radiation, ambient temperature and wind velocity in the history of the experiment (Feb. 15, 2018) at the Solar Research Site at the Universiti Teknologi PETRONAS (UTP), Perak, Malaysia. The location has latitude of 4.42 degrees North, longitude $100.98^{\circ} \mathrm{E}$, above sea level $24.23 \mathrm{~m}$ ). The average hourly solar radiation was 889 $\mathrm{W} / \mathrm{m}^{2}$ and the maximum wind velocity was $1.99 \mathrm{~m} / \mathrm{s}$. The mass flow rate for the solar cycle was $2(1 / \mathrm{m})$ and the experiment was conducted from 9:00 AM to 18:00 PM.

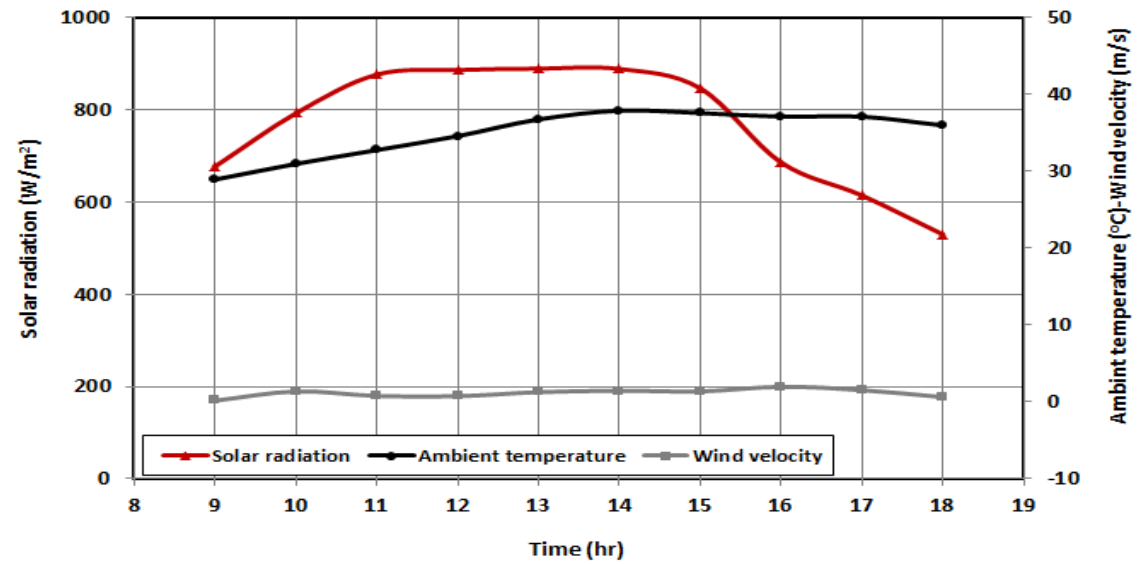

Fig. 3. Portrays an average of hourly values for peak daily radiation of each month.

To evaluate the performance of evacuated tubes and simulate the effect of changing the above-mentioned parameters, we have performed a parametric analysis after employing the varying solar radiation in Perak, Malaysia. This variation is important because it allows us to study the impact of solar intensity on the energy input of the receiver. Fig. 4 shows the mentioned relationship. The energy input increases with increased solar irradiation with the increase ranging from 3429 to $5684 \mathrm{~W}$ and 1879 to $3088 \mathrm{~W}$ at $9 \mathrm{AM}$ and 13:18 PM for preheater and superheater respectively.

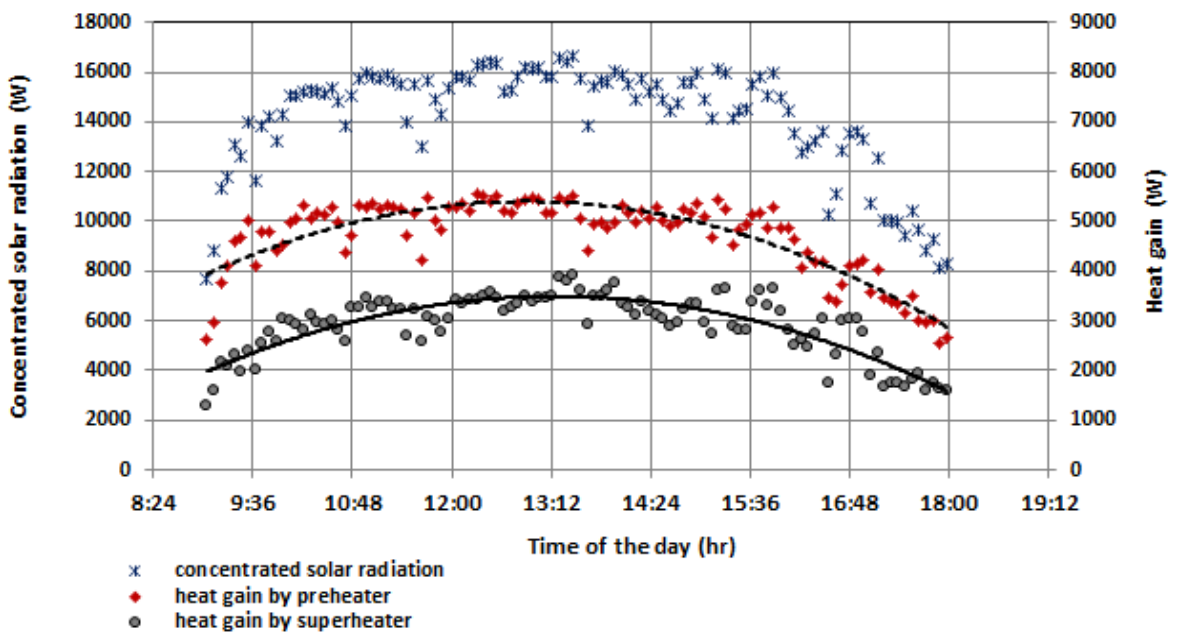

Fig. 4. Effect of solar irradiation on the useful energy from the receiver. 
The efficiency is not much influenced by increasing the flux of solar energy. As Fig. 5 depicts, the efficiency increase is only from $71.6 \%$ to $73.5 \%$, a total of $1.9 \%$. This can be attributed to the fact that a low solar flux also reduces the useful energy generation rate of the receiver and with the knowledge that the flux is also low; the efficiency will remain the same [6].

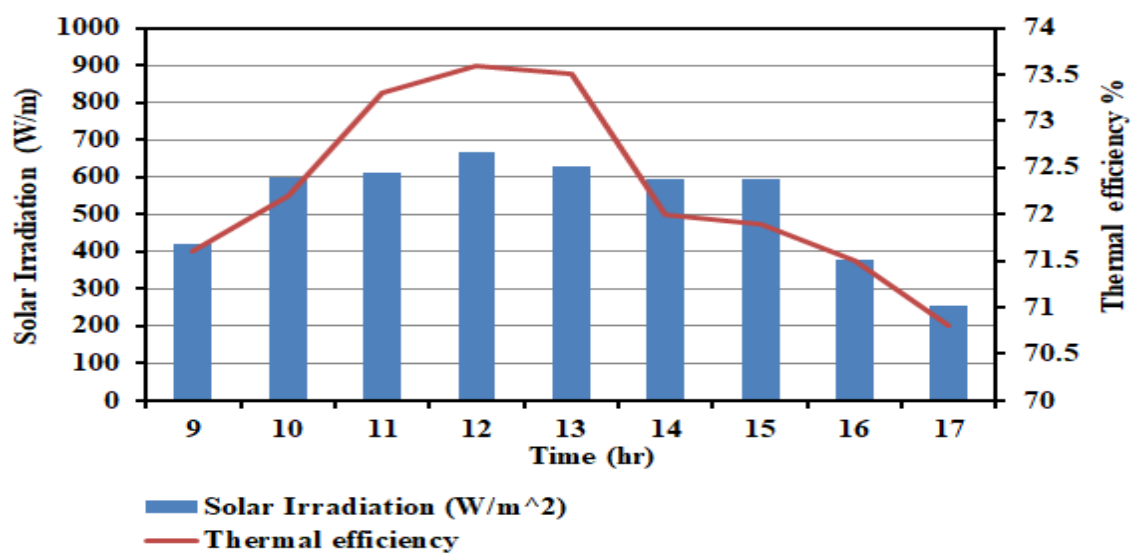

Fig. 5. Effect of solar irradiation on the thermal efficiency.

\section{Conclusions}

This paper is a comprehensive presentation of the proposed novel design of the receiver and its field performance. The results can be recapitulated as follows:

- To minimize spillage from the receiver, the zigzag distribution was used to increase the number of tubes to intercept as much solar energy as possible.

- The biggest losses effect on the optical efficiency is the cosine and spillage.

- The thermal efficiency of the receiver was about $72 \%$.

\section{References}

1. L.S. Conradoa, A. Rodriguez-Pulido, and G. Calderóna. Renew Sustain Energy Rev, 67,1345-59.2017.

2. V. Kumar, Shrivastava RL, and Untawale SP. Renew Sustain Energy Rev; 4, 37690.2014.

3. B. Zou, J. Dong, Y. Yao, and Y. Jiang. Solar Energy; 147, 189-201.2017.

4. S. T. Mohammad, H. H. Al-Kayiem, M. K. Assadi, S. I. U. Gilani, and A. K. Khlief, MATEC Web of Conferences, 131, 02008 (2017).

5. C. Xu, Z. Wang, X. Li, F. Sun, Appl. Thermal Eng., 31, 3904-3913, (2011).

6. M. S. Shahin, M. F. Orhan, and F. Uygul, Solar Energy, 136, 183-196, (2016). 